\title{
TALBOT'S LAW AS APPLIED TO THE ROTATING SECTORED DISK.
}

By Edward P. Hyde.

I. Introduction.

2. Theoretical Discussion.

a. Radiation from a cylindrical source.

b. Method of mean distances.

3. Apparatus and Methods.

a. General method.

b. Sources.

c. Disks.

d. Details of methods.

White light.

Colored light.

4. Experimental Results.

a. Effect of speed.

b. Disks.

c. White light.

d. Colored light.

5. Conclusions.

\section{INTRODUCTION.}

The rotating sectored disk is one of the most valuable adjuncts in photometric investigation, and yet from the first announcement by Talbot ${ }^{1}$ of the law governing its operation until the present time the application of the sectored disk has been limited by a widespread doubt of the general truth of the law announced by Talbot. This law is stated by Helmholtz as follows: "If any part of the retina is excited with intermittent light, recurring periodically and

${ }^{1}$ Phil. Mag., Ser. 3, Vol. 5, p. 32I; 1834.

${ }^{2}$ Physiolog. Optik, II Auflage, p. 483. 
regularly in the same way, and if the period is sufficiently short, a continuous impression will result, which is the same as that which would result if the total light received during each period were uniformly distributed throughout the whole period."

Talbot's law is thus a statement of physiological rather than of physical phenomena, and depends for its explanation on the action of the eye. Talbot recognized this and was consequently led to state, "I need hardly observe that it would be illogical to assert à priori the existence of this law of optics, however simple and natural it may appear, unless we were perfectly well acquainted with the circumstances which accompany the action of light upon the retina, which is very far from being the case. Its proof can rest on experiment alone, and by that it seems to be most satisfactorily established."

Many experimenters since Talbot have investigated the law, notably Plateau, ${ }^{1}$ Helmholtz, ${ }^{2}$ Fick, ${ }^{3}$ Kleiner, ${ }^{4}$ Wiedemann and Messerschmidt, ${ }^{5}$ and more recently Ferry, ${ }^{6}$ and Lummer and Brodhun. ${ }^{7}$ Of the earlier investigators Platean, Helmholtz, Kleiner, and Wiedemann and Messerschmidt verified the law within their range of experimental error, which was always several per cent. Fick, from theoretical considerations of the complex action of the eye as shown in the phenomena known as "Anklingen" and "Abklingen," concluded that a law as simple as that of Talbot is impossible. $\mathrm{He}$, moreover, repeated Plateau's experiments and was led to the conclusion that Talbot's law is not true in general, but that with more intense illuminations the action of the intermittent light is stronger than it should be according to the law, and that perhaps with very weak illumination the effect is reversed. Aubert ${ }^{8}$ criticised Fick's conclusions on the ground that the deviations which he found were of the same order of magnitude as his experimental error, and that therefore his results verified the law to within the limit of accuracy of his experiments.

\footnotetext{
${ }^{1}$ Pogg. Annalen der Physik, 35, p. 457; IS35.

${ }^{2}$ Physiolog. Optik, II Auflage, p. 483.

${ }^{3}$ Reichert's u. du Bois-Reymond's Archiv., p. 739; IS63.

${ }^{4}$ Pflüger's Archiv. 18, p. 542; I878.

${ }^{5}$ Wied. Ann. 34, p. 465; I888.

${ }^{6}$ Phys. Rev. 1, p. 338; I 893.

${ }^{7}$ Zs. für Instrumentenkunde, 16, p. 299; 1896.

${ }^{8}$ Physiologie der Netzhaut, p. 35r.
} 
Of the two more recent investigations Ferry verified the law for white light, but found quite large errors when the light transmitted throngh the rotating sectored disk was of a bluer quality than that incident on the other side of the photometer screen. His method consisted in mounting two sources of light on the photometer bench, one at each end, and interposing in the path of the rays from one source a rotating sectored disk with variable openings. The disk was mounted on a movable support so that it could readily be introduced in the path of the rays and quickly removed again after a reading had been made.

In this way, using as sources two $16 \mathrm{cp}$ incandescent electric lamps of approximately the same color, he found the law to be verified for all openings of the sector down to a total angle of $24^{\circ}$. Moreover, as the voltage on the lamps was changed from 70 to 20 volts, provided the two lamps were changed together, the result was the same as before. He then mounted a $50 \mathrm{cp}$ incandescent lamp at the disk end of the bar and a $16 \mathrm{cp}$ lamp at the other end, and found as before that Talbot's law is verified if the two lamps are of approximately the same color. If, however, the $50 \mathrm{cp}$ lamp was burned at a voltage much higher than the normal, or if a piece of slightly tinted blue glass was interposed in the path of the rays intercepted by the sectored disk, a very appreciable deviation from Talbot's law was introduced when the opening of the disk was less than $180^{\circ}$, the deviation increasing as the opening was made smaller. Using successively an enclosed arc lamp and a lime light on the sectored disk side of the photometer and an incandescent lamp on the other side, he obtained deviations amounting to 5 per cent and Io per cent, respectively, at $24^{\circ}$, the deviation in each case being approximately zero when the opening of the disk was greater than $180^{\circ}$. In all cases in which deviations from the law were found the disk let through less light than that demanded by Talbot's law.

As a result of his observations Ferry concluded that althongh Talbot's law is true for white light, "with mixed light containing elements of different luminosity shining upon the retina, a rotating sectored disk will appear to not cut off all the elements in equal proportion, but will intercept most strongly the elements of low luminosity." Further, "with any given light the error introduced 
by the use of the rotating sectored disk increases as the aperture of the disk diminishes," although "with ordinary illuminants, the error is negligible when the total aperture of the disk is more than one-half the entire disk, but rapidly increases as this aperture is diminished."

Inasmuch as experiments made by the writer yielded results quite different from those of Ferry, it seems desirable to examine carefully his experiments and results. Unfortunately, owing to lack of detail in Ferry's paper, it is difficult to subject these to a searching criticism, and yet there are several points to which it may be well to call attention.

First, it is to be noticed that when the two incandescent lamps were varied simultaneously from 70 to I 20 volts-i. e., over quite a large range of color-no error was observed, but that when one lamp was burned at a voltage somewhat higher than normal while the other was kept at the normal voltage a relatively large error was found. The question immediately arises: What would have been the result if the second lamp also had been burned at a voltage somewhat higher than normal? Since there is nothing in the paper to indicate the normal voltages of the two lamps, which were varied from 70 to I 20 volts, we are at a loss to answer the question. It is probable, however, that the upper limit of such a large range would represent a voltage at least as high, if not higher, than the normal. On this assumption we would conclude that although the change in color produced by a decrease in voltage from 120 to 70 volts is accompanied by no error in Talbot's law, the color change due to a rise in voltage somewhat above the normal causes a relatively large error in the law for openings of small angles. In other words, the color corresponding to the normal voltage is a critical color.

Since this is quite improbable, we are led to conclude that the cause of the error when the lamp at the disk end of the bar was raised to a voltage somewhat higher than the normal, while the other lamp was kept at the normal voltage, is to be found in the color difference which existed on the two sides of the screen. While it is difficult to understand why the color of one side should influence the effect of the rotating sector on light from the other lamp, it is to be noted that in all probability a different form of photometer was used when the color difference existed, and this 
might perhaps account for the error. Ferry states in his introduction that for lights of the same color a Lummer-Brodhun photometer was used, but that when a considerable color difference existed a Bunsen photometer was employed. When the difference in color on the two sides was small, he found the Nichols-Ritchie photometer to give the best results. In describing his experiments he does not state explicitly, however, which form of photometer he used in each case.

Because of this lack of definiteness in Ferry's paper it seemed very desirable to make further experiments on the influence of color on the action of the rotating sectored disk. There are also two very definite reasons why Ferry's results are open to criticism. First, since the absolute illumination of the photometer screen was always much greater without the disk than with it, the Purkinje effect would produce errors in the results when the two sources differed to any extent in color. Secondly, the inverse square law applies rigorously only to point sources and can not be assumed à priori for such an extended source as the filament of an incandescent lamp, particularly

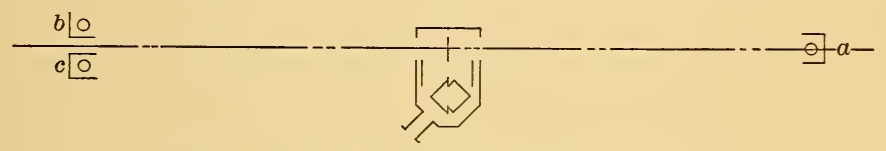

Fig. 1.-Lummer and Brodhun's Arrangement.

when it is surrounded by the reflecting and refracting glass bulb, which alters the curvature of the emitted light to such an extent that in some directions sharp images of the filament are formed sereral meters away. The lime light and the enclosed arc lamp, apart from the possible errors due to the inapplicability of the inverse square law, would seem to be unsuitable for accurate work because of their great unsteadiness.

The most satisfactory work that has been done on Talbot's law is that of Lummer and Brodhun at the Physikalisch-Technische Reichsanstalt. These investigators first verified the law for white light down to $50^{\circ}$ total opening, by using two incandescent electric lamps, thus far being merely a repetition of Ferry's work. Recognizing, however, the possible error due to the inapplicability of the inverse square law, they modified their experiments in the following manner. Three incandescent lamps were mounted on the photometer bench, as shown in Fig. I. Lamp $a$ burned continuously but lamp 
$b$ and lamp $c$ were burned successively, and the current through each was regulated until each produced approximately the same illumination of the screen. They were then both burned at the same time, the rotating disk with a total opening of $\mathrm{I} 80^{\circ}$ was placed between them and the photometer, and a balance was obtained by moving lamp $\alpha$. In this way, since the distance from lamp $a$ to the screen remained approximately constant, errors in the application of the inverse square law entered only as second order effects and were hence negligible. In a similar way each lamp in turn was burned with the disk set at $\mathrm{I} 80^{\circ}$ total opening, and then both were burned simultaneously with the disk set at $90^{\circ}$. In every case the deviations from the law were found to be of the same magnitude as the experimental error, which was less than one-half per cent. It is not stated, however, how far the process was carried, except that it was not extended to very small angular openings.

Although the results of Lummer and Brodhun are conclusive as far as they go, attention should be called to the fact that because the observational error was less than one-half per cent, it does not necessarily follow that Talbot's law was verified to such a high accuracy for all angular openings that they used. Since their method of observation consisted in verifying the law step by step, between $360^{\circ}$ and $180^{\circ}, 180^{\circ}$ and $90^{\circ}$, etc., the error between $360^{\circ}$ and, say, $221 / 2^{\circ}$ would be distributed over four intervals, so that though the error within each interval may be less than one-half per cent it is possible that an error of I or 2 per cent might exist between $360^{\circ}$ and $221 / 2^{\circ}$ without being detected. This fact, together with a desire to check Ferry's results for colored light, led the writer to make the experiments described in the following pages.

In the investigation of 'Talbot's law by the use of the rotating sectored disk some other law of the variation of the intensity of illumination must be assumed. Of the several possible ways of varying the intensity of illumination of the screen the method of varying the distance between the source and the screen is the simplest and most satisfactory, but presupposes the knowledge of the law of variation of the intensity of illumination with the distance for the source to be used. If the source is a point source the inverse square law holds; if the source is not a point source-and no actual source is strictly a point source-it must either be shown that within the limits of accuracy of the experiments the deviations from the inverse square 
law are negligible under the conditions under which the source is to be used, or else the deviations from this law must be determined and applied.

The source to be used must not only have the law of variation of intensity of illumination with distance known, but must also be constant and intense. The incandescent lamp fulfills the last two conditions, but, as heretofore pointed out, it does not fulfill the first condition.

It occurred to the writer to try as a source a direct current Nernst glower without a globe. Although the only one of the above conditions that could be postulated à priori was the intensity, experi-

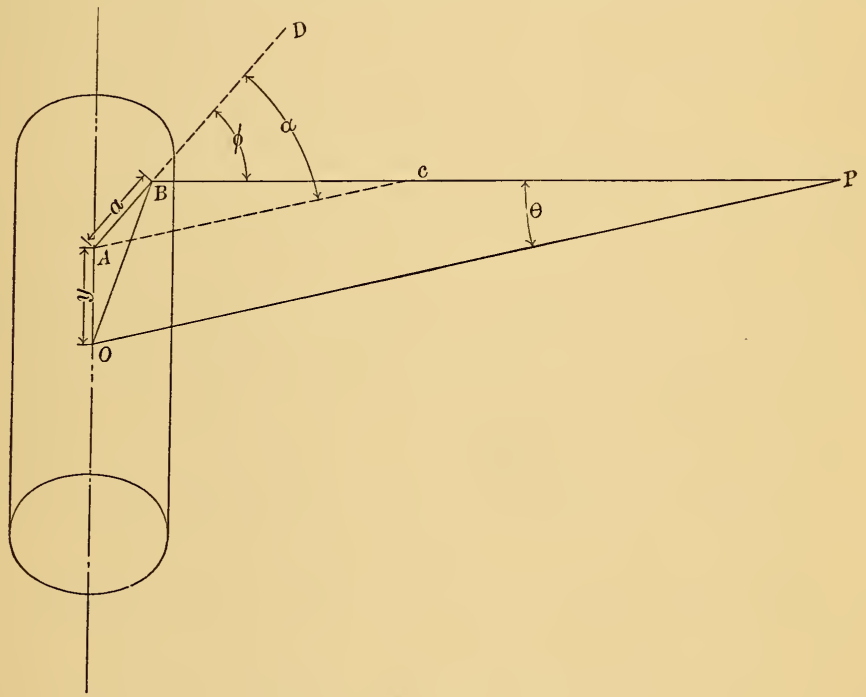

Fig. 2.-Radiating Cylinder.

ment showed that the glower remained sufficiently constant under certain conditions which could be readily obtained, and the following theoretical considerations led to the conclusion that the inversesquare law can be applied to the Nernst glower to within negligible errors if the glower is not brought closer to the photometer screen than 20 or $30 \mathrm{~cm}$. The Nernst glower was therefore used through the experiments, and with entire satisfaction.

\section{THEORETICAL DISCUSSION.}

(a) Radiation from a Cylindrical Source.-Let us assume that the Nernst glower is a radiating circular cylinder of radius $a$, length $2 h$, 
and uniform specific light intensity $i$. The problem then consists in determining the law of variation of the intensity of illumination with the distance for a uniform radiating cylinder.

Let us further assume Lambert's cosine law for the radiating cylinder. Although this law holds rigorously for black bodies only, the resulting error in the comparison of illuminations at different distances would be quite small. If, then, we let $\phi$ (Fig. 2) be the angle of emission for any element of surface $d S$ of the radiating cylinder; $\theta$ the angle of incidence of any ray on a screen at $P$ placed at right angles to $\overline{\mathrm{OP}}$, where $\overline{\mathrm{OP}}$ lies in the plane perpendicular to the axis of the cylinder at its middle point, $O ; r$ the distance from the element $d S$ to the screen at $P$; then the intensity of illumination of the screen at $P$ is

$$
J=\iint \frac{i \cos \phi \cos \theta d S}{r^{2}}
$$

taken over that part of the curved surface of the cylinder convex toward $P$.

Expressing all the quantities involved in the above equation in terms of the two cylindrical coordinates $a$ and $y$, we get for the intensity of illumination at $P$, at a distance $l$, from the axis of the cylinder-

$$
J=i a \iint \frac{(l \cos a-a)(l-a \cos a)}{\left(a^{2}+l^{2}-2 a l \cos a+y^{2}\right)^{2}} d a d y
$$

in which the limits of $y$ are $(-h,+h)$, and the limits of $a$ are $\left(-\cos ^{-1} \frac{a}{l},+\cos ^{-1} \frac{a}{l}\right)$.

The integra $1^{1}$ of the above expression is

$$
\begin{aligned}
J= & \frac{i}{l}\left\{a \cos ^{-1} \frac{l^{2}-a^{2}-h^{2}}{l^{2}-a^{2}+h^{2}}\right. \\
& \left.+h\left[(q+\mathrm{I}) \sqrt{\frac{1}{q}} \cot ^{-1} \sqrt{\frac{p}{q}}-2 \cot ^{-1} \sqrt{p}\right]\right\}
\end{aligned}
$$

where

$$
p=\frac{l+a}{l-a}, q=\frac{(l+a)^{2}+h^{2}}{(l-a)^{2}+h^{2}}
$$

${ }^{1}$ This integral was obtained by Prof. A. S. Chessin, of Washington University, to whom the writer desires to express his indebtedness. 
It only remains to substitute for the constants $a$ and $h$ in the above equation the numerical values pertaining to a Nernst glower and then to compute the value of $J$ for different distances, $l$. Before doing this, however, it is interesting to note, in passing, the form which the equation assumes when we make $h$ approach infinity. Under this condition $q$ approaches unity, and so in the limit. equation (3) becomes

$$
J=\frac{\pi i a}{l}
$$

In other words, the intensity of illumination due to an infinitely long uniformly radiating cylinder varies inversely as the first power of the distance from the axis of the cylinder, a result which also follows from purely physical considerations of the normal flow of energy across coaxial cylindrical surfaces.

Let us now substitute the dimensions of the Nernst glower in equation (3), compute the intensity of illumination at different distances, $l$, and compare the relative values with those obtained on the assumption of the inverse square law. Two sizes of glowers were used in the investigation, 88-watt glowers and 44-watt glowers. The dimensions of the former are $h=7.5 \mathrm{~mm}, a=0.6 \mathrm{~mm}$. Of the latter, $h=6 \mathrm{~mm}, a=0.4 \mathrm{~mm}$. If, then, in the above equation we put $h=\mathrm{IO} \mathrm{mm}$ and $a=\mathrm{I} \mathrm{mm}$ we shall include both glowers, and

\section{TABLE I.}

Deviation from the Inverse Square Law of the Radiation of a Cylinder $20 \mathrm{~mm}$ long and $1 \mathrm{~mm}$ radius.

\begin{tabular}{|c|c|c|c|c|c|}
\hline Distances, $l$ & \multicolumn{2}{|c|}{$J$ (Direct Evaluation) } & \multicolumn{2}{|c|}{$J$ (Inverse Square Law) } & Deviation \\
\hline 3000 & 1.0000 & $\times J_{3000}$ & 1.0000 & $x J_{3000}$ & $\pm 0.00 \%$ \\
\hline 2000 & 2.2500 & 66 & 2.2500 & "6 & +0.0066 \\
\hline 1000 & 9.0045 & 6 & 9.0000 & 6 & +0.0566 \\
\hline 500 & $3.6040 \times 10$ & "6 & $3.6000 \times 10$ & 66 & +0.11 "6 \\
\hline 200 & $2.2545 \times 10^{2}$ & "6 & $2.2500 \times 10^{2}$ & “ & +0.20 " \\
\hline 100 & $9.0081 \times 10^{2}$ & "6 & $9.0000 \times 10^{2}$ & "6 & +0.09 "6 \\
\hline 80 & $1.4049 \times 10^{3}$ & "6 & $1.4062 \times 10^{3}$ & “ & -0.09 ، \\
\hline 50 & $3.5593 \times 10^{3}$ & 6 & $3.6000 \times 10^{3}$ & 6 & -1.13 ، \\
\hline
\end{tabular}

the deviations from the inverse square law which we shall find will be greater than those incident to the use of either glower. The 
results of this substitution for different distances, $l$, are shown in Table I and Fig. 3. In the first column of Table I are given the distances, $l$, expressed in millimeters, for which the values of $J$ were computed. The second column contains the ratios of the intensities at the different distances, $l$, to that at $l=3000 \mathrm{~mm}$, as obtained by direct substitution in equation (3); and the third column gives the same ratios obtained by the inverse square law. The percentage errors are shown in the fourth column, in which $(+)$ means that the intensity of illumination determined by direct evaluation of the integral of equation (3) is relatively greater, as compared with the intensity at $l=3000 \mathrm{~mm}$, than the value obtained by the inverse square law from the intensity at $l=3000 \mathrm{~mm}$. This is shown in Fig. 3, in which abscissas are distances, $l$, and ordinates are per-

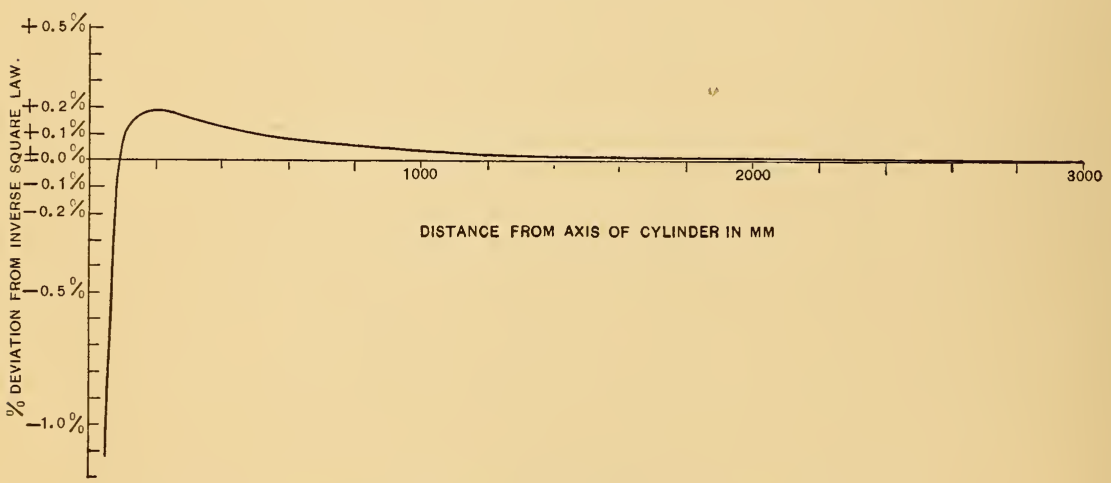

Fig. 3.-Deviation of Radiation of Cylinder from Inverse Square Law.

centage deviations from the inverse square law, as deduced from the value of the intensity at $l=3000 \mathrm{~mm}$. It is thus seen that the value of $J$ between $l=3000 \mathrm{~mm}$ and $l=90 \mathrm{~mm}$ is greater (as compared with $J$ at $l=3000 \mathrm{~mm}$ ) than the value of $J$ deduced on the assumption of the inverse square law, the maximum deviation being about +0.2 per cent. At distances less than about $90 \mathrm{~mm}$ the intensity becomes very much less than the values demanded by the inverse square law, the deviation at $l=50 \mathrm{~mm}$ being over $\mathrm{I}$ per cent.

Since in the experiments described below the extreme distances used were $l=3000 \mathrm{~mm}$ and $l=500 \mathrm{~mm}$ the maximum error on the assumption of the inverse square law for the Nernst is approximately O.I per cent, which is entirely negligible. Moreover, the errors given in Table I and Fig. 3 were deduced for a cylinder having the 
dimensions $h=\mathrm{IO} \mathrm{mm}, a=\mathrm{I} \mathrm{mm}$, which are somewhat greater than the dimensions of an 88-watt Nernst glower, and much greater than the dimensions of a 44-watt glower. Hence the true errors for the Nernsts are probably less than those given in the table.

It should be stated that the above theory was based on the assumption of a true circular cylinder with constant specific light intensity, $i$. The Nernst glower does not fulfill either of these conditions rigorously. It frequently becomes warped after burning for some hours, and direct experiment reveals the fact that the intensity; $i$, is different at different parts of the filament. These deviations probably remain constant, however, during a series of experiments, and so only introduce differential errors in the relative intensities of illumination at different distances.

(b) Method of Mean Distances. - In the above investigation $l$ was defined to be the distance from the center of the cylinder to the photometer screen, the axis of the cylinder being parallel to the screen, and the centers of both cylinder and screen lying in the same plane perpendicular to the axis of the cylinder. In the experimental method employed it was found difficult to measure this distance directly by the use of the scale on the photometer bar. The glower was therefore mounted in a horizontal position in a socket that could be turned about a vertical axis through its center. The position of the axis of rotation on the bar was shown by an index attached to the carriage on which the socket was mounted, so that distances between the axis of rotation and the photometer could be read off the scale on the bar. The center of the glower was now placed approximately in the axis of rotation, and readings were made first with one side of the glower, [designated $(+)]$ and then with the other side of the glower [designated $(-)]$ turned toward the photometer. In each case the distance was measured to the axis of rotation and the mean of the two readings taken. This mean distance was the distance used in the comparison of intensities of illumination, and it must hence be shown that the square of the ratio of one mean distance, $x$, to another mean distance, $x^{\prime}$, gives the true value of the ratio of the two corresponding illuminations, $J$ and $J^{\prime}$.

Before proceeding to this let us consider a different way of interpreting the deviations of the law of radiation of the cylinder from the inverse square law. Since for all distances greater than $l=90$ 
$\mathrm{mm}$ the intensity of illumination compared with the intensity at $l=3000 \mathrm{~mm}$ is slightly greater than that for a point source, we may consider the cylinder as a point source, the effective center of radiation of which is at the center of the cylinder for $l=3000 \mathrm{~mm}$, but for distances between $l=3000 \mathrm{~mm}$ and $l=90$

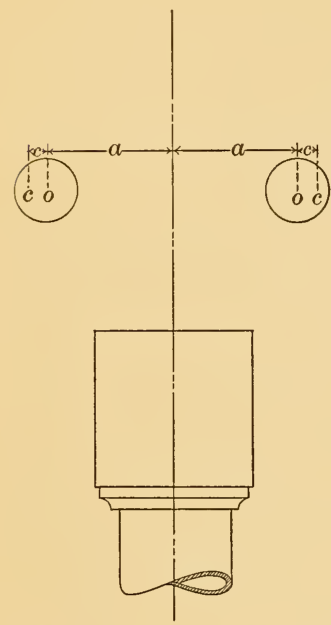

Fig. 4.-Displacement of Axis of Cylinder from Axis of Socket. min it is displaced a variable small anount toward the photometer screen. Hence, as the deviations from the inverse square law are very small for all distances used in the experiments, we can take the percentage error in distance to be one-half the percentage error in intensity of illumination. If, therefore, we take one-half the ordinates of Fig. 3 we obtain the percentage errors in the effective distances. In this way we can determine for any distance the displacement, $c$, of the effective center of radiation from the geometrical center of the cylinder.

We will suppose now that the geometrical center of the cylinder is at a distance, $a$, from the axis of the socket (Fig. 4). Suppose further that the photometer screen has an intensity of illumination, $J$, the distance from the axis of the socket to the screen being $x_{1}$ when the $(+)$ side of the Nernst is turned toward the screen, and $x_{2}$ when the $(-)$ side is turned in that direction. If now $I_{1}$ and $I_{2}$ are the effective intensities of the $(+)$ and $(-)$ sides of the Nernst, respectively, considered as a point source,

$$
J=\frac{I_{1}}{\left(x_{1}-a-c\right)^{2}}=\frac{I_{2}}{\left(x_{2}+a-c\right)^{2}}
$$

In a similar way the equation corresponding to an illumination, $J^{\prime}$ is

$$
J^{\prime}=\frac{I_{1}}{\left(x_{1}^{\prime}-a-c^{\prime}\right)^{2}}=\frac{I_{2}}{\left(x_{2}^{\prime}+a-c^{\prime}\right)^{2}}
$$

Hence the true ratio of $J$ to $J^{\prime}$ is

$$
\frac{J}{J^{\prime}}=\left(\frac{x_{1}{ }^{\prime}-a-c^{\prime}}{x_{1}-a-c}\right)^{2}=\left(\frac{x_{2}{ }^{\prime}+a-c^{\prime}}{x_{2}+a-c}\right)^{2}
$$


which, by composition, becomes

$$
\frac{J}{J^{\prime}}=\left(\frac{x_{1}^{\prime}+x_{2}^{\prime}-2 c^{\prime}}{x_{1}+x_{2}-2 c}\right)^{2}
$$

Or, if we put

$$
\begin{aligned}
\quad x=\frac{x_{1}+x_{2}}{2}, x^{\prime}=\frac{x_{1}^{\prime}+x_{2}^{\prime}}{2} \\
\frac{J}{J^{\prime}}=\left(\frac{x^{\prime}-c^{\prime}}{x-c}\right)^{2} \\
=\left(x^{\prime 2}-2 c^{\prime} x^{\prime}+c^{\prime 2}\right)\left(\frac{I}{x^{2}}+\frac{2 c}{x^{3}}+\frac{3 c^{2}}{x^{4}}+e t c .\right) \\
=\left(\frac{x^{\prime}}{x}\right)^{2}\left(\mathrm{I}-\frac{2 c^{\prime}}{x^{\prime}}+\frac{c^{\prime 2}}{x^{\prime 2}}\right)\left(\mathrm{I}+\frac{2 c}{x}+\frac{3 c^{2}}{x^{2}}+e t c .\right) \\
=\left(\frac{x^{\prime}}{x}\right)^{2}\left(\mathrm{I}-\frac{2 c^{\prime}}{x^{\prime}}+\frac{2 c}{x}\right)
\end{aligned}
$$

to within negligibly small quantities. From this equation, or better from equation (10), it follows that for a true point source at the center of the cylinder the ratio of the intensities obtained by taking the mean distances $x$ and $x^{\prime}$ is the same as that obtained from the actual distances $x_{1}-a$ and $x^{\prime}{ }_{1}-a$, or $x_{2}+a$ and $x_{2}{ }^{\prime}+a$, since for a true point source $c=c^{\prime}=0$ and from equations (7) and (IO)

$$
\frac{J}{J^{\prime}}=\left(\frac{x_{1}^{\prime}-a}{x_{1}-a}\right)^{2}=\left(\frac{x_{2}^{\prime}+a}{x_{2}+a}\right)^{2}=\left(\frac{x^{\prime}}{x}\right)^{2} \text {. }
$$

In the actual case of the cylinder, $c$ and $c^{\prime}$ have very small values, as pointed out above. In fact since $\frac{c}{x} \times$ IOO is the percentage distance correction, and $\frac{2 c}{x} \times$ IOO is the percentage deviation of the intensity from the inverse square law, it follows that $\frac{2 c}{x}$ is $\frac{I}{I O O}$ of the ordinate of the curve of Fig. 3 expressed as a decimal fraction, or is equal to the ordinate of the curve expressed in per cent. Since the greatest range of distance used was between $l^{\prime}=\left[x^{\prime}-a\right]=3000 \mathrm{~mm}$ 
and $l=[x-a]=500 \mathrm{~mm}$ we see from the curve of Fig. 3 that $c^{\prime}=0$ and $c=+$ O.I I per cent, so that [eq. (I.I)]

$$
\frac{J}{J^{\prime}}=\left(\frac{x^{\prime}}{x}\right)^{2}(1-0+0 . \operatorname{II} \%)
$$

in which the correction is negligible.

Hence the method employed of taking the mean of the $(+)$ and $(-)$ readings gives absolutely true results for a point source, and for a cylinder the errors are only those incident to the deviation from the inverse-square law of the radiation of the cylinder.

\section{APPARATUS AND METHODS.}

(a) General Method. -The photometer bench on which the measurements were made is a Reichsanstalt precision photometer bench $250 \mathrm{~cm}$ long, supplied with a Lummer-Brodhun contrast screen. In the experiments with disks of small opening it was necessary to use greater distances than could be obtained on the $250 \mathrm{~cm}$ bar. In these cases an extension was fitted to one end of the bench, increasing its length by about $175 \mathrm{~cm}$. In all the experiments except those in which there was a decided color difference the contrast principle was used but in the cases of great color difference the absorption strips producing the contrast were removed and the setting was made for a match.

Throughout the experiments the substitution method was employed. Thus the source at the right end of the bar was merely used as a comparison lamp. ${ }^{1}$ The carriage on which it was mounted was connected rigidly by means of adjustable links to the carriage supporting the photometer screen and at a suitable distance to produce the desired illumination of the screen. The comparison lamp thus moved with the screen, remaining at a constant distance from it, except in so far as slight irregularities in the ways produced small variations in the distance, depending upon the positions of the carriages on the bar. These eccentricities were carefully studied for all positions of both carriages on the bar and the results were tabulated, so that the variations in the distance between the comparison lamp and the screen, as the latter was moved back and forth

"Hereafter the lamp on the right will be referred to as the "comparison lamp," in distinction from the "test lamp" on the left. 
on the bar, could be determined directly. Since, however, in nearly every experiment the position of the photometer was approximately the same with the sectored disk stationary and rotating, and since regions of the bar were selected which were approximately true, in general no correction was necessary for the distance between the comparison lamp and the screen. Hence the illumination on the right side of the screen remained constant to within the variations of the comparison source itself.

On the left side of the photometer the test Nernst and the sectored disk were mounted. Fig. 5 is a diagrammatic sketch of the

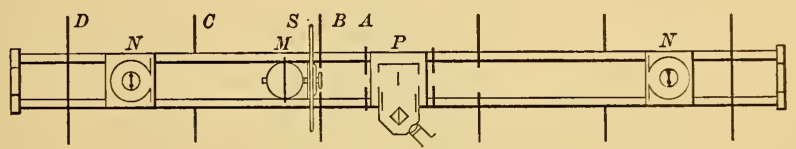

Fig. 5.-Diagrammatic Sketch of Photometer Bench.

general arrangement, in which $\mathrm{A}, \mathrm{B}, \mathrm{C}$, and D are diaphragms covered with black velvet, which were always so arranged that no stray light could reach the photometer screen except by reflection from the black velvet at an angle approximately equal to 90: The magnitude of this stray light, when the walls of the room were white and were rather strongly illuminated, was found by a previous investigation ${ }^{1}$ to be entirely negligible. $M$ is a small spherical motor, which carries on its shaft the sectored disk $S . \quad N N$ are the two sources and $P$ is the photometer screen.

(b) Sources.-Direct current Nernst glowers were used throughout the investigation for the test source at the disk end of the bar, and in most of the measurements a glower was used for the comparison lamp. When the effect of color difference was investigated an incandescent lamp at low voltage was

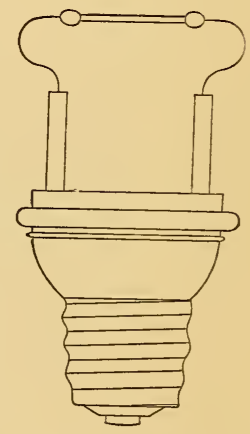

Fig. 6.-Nernst Glower Mounted on Extension Plug. used for a comparison lamp, and in some few experiments on colored light an incandescent lamp was substituted for the comparison Nernst. As stated above, the glowers were burned without any globes around them, since reflection, refraction, and diffusion of the light by the globe might produce serious errors. Moreover the

${ }^{1}$ Bureau of Standards Bulletin No. 3, p. 417.

24353-No. $\mathrm{I} \longrightarrow \mathrm{O} 6-2$ 
glowers were not provided with the customary ballast resistance. They were mounted on extension plugs, as shown in Fig. 6, and were operated with constant current on a storage-battery circuit of 250 volts, of which approximately $\mathrm{r} 5 \mathrm{O}$ volts was taken up in rheostats. This series resistance took the place of the customary ballast resistance and served to keep the current approximately constant.

The electrical measurements were made in terms of a Weston standard cell by means of a potentiometer. Thus, the current was measured by the difference in potential across a standard resistance and the voltage was obtained by the use of a I0o,000 ohm multiplier.

The original plan was to leave the Nernst glowers entirely uncovered, but it was found that due to air currents the resistance of the glowers changed continually, so that it was impossible to maintain the current in the glowers constant, and the fluctuations in the volt-

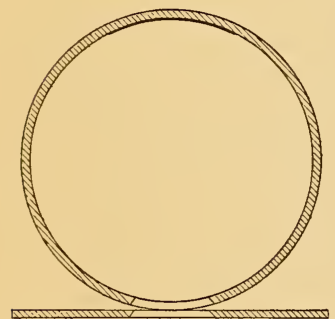

Fig. 7.- Horizontal Section of Hood through Opening. age were so great as to preclude the possibility of measurement closer than to several tenths of I per cent. Moreover, the effect of the rotating disk in the neighborhood of the Nernst was evident both in the current and in the voltage. I was thus led to try the effect of partially surrounding the Nernsts with hoods. To this end two pieces of brass tubing $40 \mathrm{~cm}$ long and $\mathrm{r} 5 \mathrm{~cm}$ diameter were each provided with a rectangular opening $\mathrm{I} \mathrm{cm}$ high and $5 \mathrm{~cm}$ wide at a distance of $28 \mathrm{~cm}$ from one end of the tube, so as to be opposite the Nernst when placed on the base of the carriage on which the Nernst was mounted. Each of these hoods was provided with a loosely fitting piece of sheet brass for a cover and was painted a dead black. Lest any stray light might be reflected into the photometer at approximately grazing incidence from the outside of the tube, a sheet of brass $25 \mathrm{~cm}$ long and $\mathrm{I}_{5} \mathrm{~cm}$ wide was covered with black velvet and fastened to the front of the hood with the black velvet turned toward the screen. This diaphragm was provided with a rectangular opening to correspond with the opening in the hood, as shown in Fig. 7, which is a horizontal section in the plane of the opening. That part of the inside of the tube which was behind the Nernst was also covered with black velvet in order to prevent any possible reflection from the painted metal surface. 


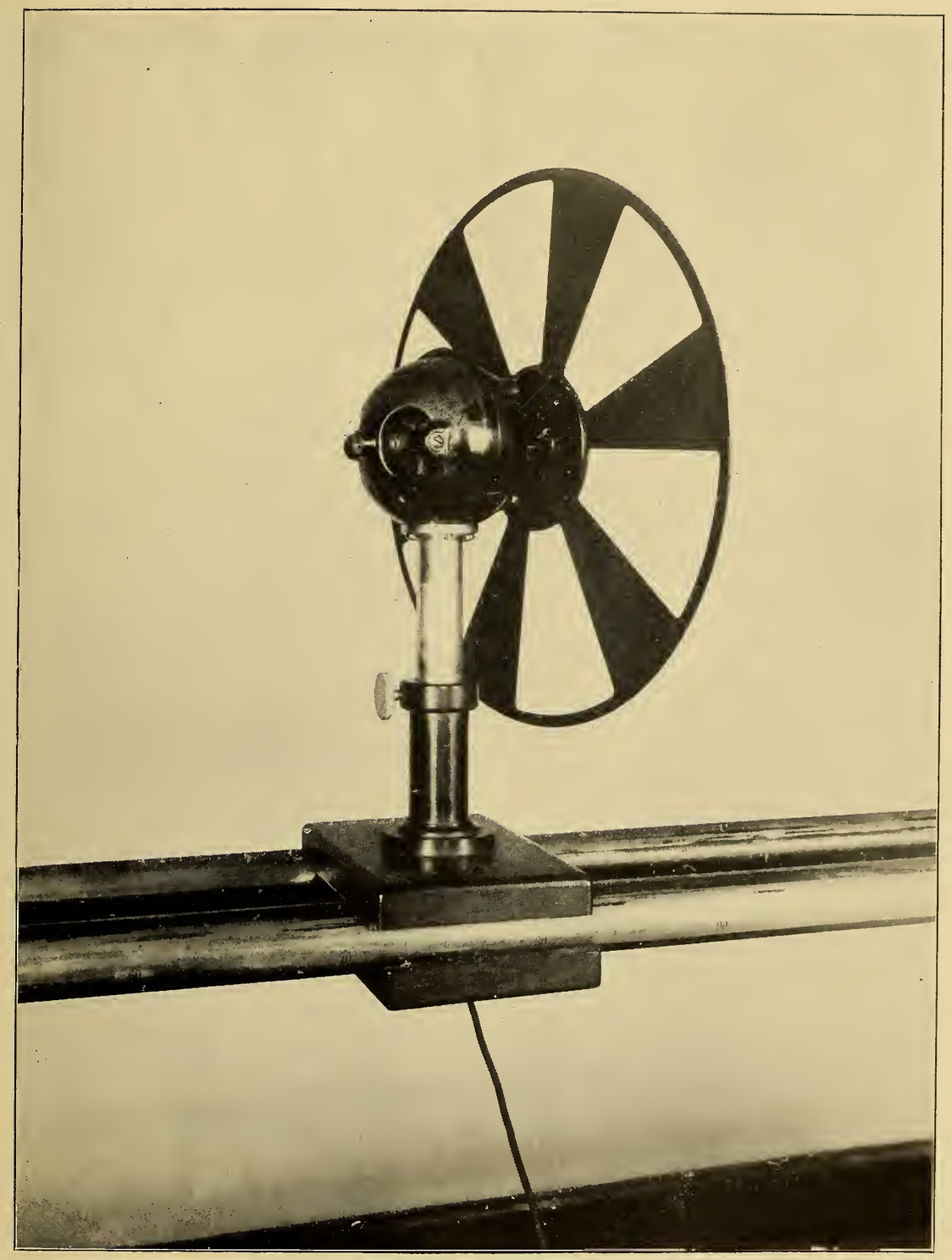

Fig. 8.-Sectored Disk Mounted on Photometer Bar. 
Under these hoods the Nernsts operated almost as steadily as incandescent lamps. The current could be maintained constant to within I or 2 parts in Io,ooo, and the voltage could usually be measured to the same accuracy. Moreover, the luminous intensity remained constant to within the limit of observational error, and the sectored disk in the neighborhood of the Nernst seemed to have no appreciable effect on its voltage at constant current, which affords a quite sensitive means of determining slight variation in the temperature of the Nernst. It was for this reason that voltage measurements were made with every series of observations.

One peculiar voltage effect vas noticed which occurred at times both when the disk was stationary and when it was rotating. The voltage would suddenly change over several tenths of a volt and then gradually creep back. As this change was usually accompanied by no perceptible variation in the luminous intensity, if the current was maintained constant, and as it seemed to occur more frequently after the Nernsts had burned for many hours, it seemed probable that it was due to the cracking of the terminals of the filament and a consequent redistribution of the current at the terminals. This hypothesis seemed to be borne out by the fact that in all old Nernsts the positive ends show large and deep cracks.

At first the presence of these sudden changes in the voltage caused doubt as to the accuracy of the results. They repeatedly occurred both while the disk was stationary and while rotating, and could not be detected at the photometer, although every other condition was maintained constant. I was therefore led to disregard them, particularly as the results obtained in sets in which there was no trace of such an effect agreed with those obtained in sets in which the effect was plainly noticeable.

Having shown that the Nernst could be depended upon for its constancy, it remained to find some convenient way of determining the distance between the center of the test Nernst and the photometer screen. The test Nernst (as distinguished from the comparison Nernst) mounted on an extension plug, was screwed into the socket of a horizontal rotator with the driving shaft removed. But although the distance from the axis of the rotator to the near surface of the plaster of Paris screen in the photometer-head was 
known for every position of the rotator and of the photometer-head, as the result of a direct calibration of the scale on the bar, the distance of the center of the Nernst from the axis of the rotator varied slightly from time to time, due to bending of the terminal wires of the Nernst on heating, etc. Hence, after each series of measurements it was necessary to re-determine the distance. It therefore occurred to the writer to use the method described briefly in the above theory. A double pointer was attached to the rotator, and by means of a corresponding pointer attached to the carriage the Nernst could be turned through $180^{\circ}$. The mean of the $(+)$ and $(-)$ readings as described above was taken in each case.

(c). Disks. - The rotating sectored disk is shown in Fig. 8. The rotating device consisted of a small spherical direct current fan motor, $9 \mathrm{~cm}$ in diameter, mounted on a base clamped to the ways. In the figure the motor and disk are turned slightly with reference to the base, so as to be seen better. The distance of the motor above the ways could be adjusted by means of the telescoping tubes which formed the column on which the motor was mounted. The frame of the motor was japanned. In order to prevent light from being reflected into the photometer-head from the smooth surface of the motor, the top of the motor was at first covered with black velvet, but since the light was incident on this at nearly grazing incidence it was thought better to substitute a small metal screen placed normal to the direction of the rays. This was accomplished by separating the two halves of the spherical shell of the motor and inserting a blackened piece of thin sheet aluminum cut to fit. This is shown in the figure.

The sectored disks were mounted directly on the shaft of the motor and the height of the motor was adjusted so that the sector cut the beam of light normally, the central ray of the beam lying in the same vertical plane as the shaft of the motor. Instead of the customary method of using a graduated variable sectored disk, it was decided to use separate disks for the different angular openings. This was decided upon partly because four such disks were at hand and partly because there was less chance for error in the calibration of the opening. The original four disks were made of aluminum about $\mathrm{I} .5 \mathrm{~mm}$ thick, and each contained six open and six solid sectors equally spaced. The total angular openings (which will here- 
after always be meant when reference is made to the opening of a disk unless it is stated otherwise) were $288^{\circ}\left(6 \times 48^{\circ}\right), 270^{\circ}\left(6 \times 45^{\circ}\right)$, $240^{\circ}\left(6 \times 40^{\circ}\right)$, and $180^{\circ}\left(6 \times 30^{\circ}\right)$. Subsequently the following disks were added: One steel disk, I. $5 \mathrm{~mm}$ thick, with total opening of $60^{\circ}$ in three sectors of $20^{\circ}$ each; two hard brass disks, $1.5 \mathrm{~mm}$ thick, with total openings of $210^{\circ}$ in six sectors of $35^{\circ}$ each, and $30^{\circ}$ in six sectors of $5^{\circ}$ each.

All of the disks were approximately $30 \mathrm{~cm}$ in diameter, and had the same general form as that shown in Fig. 8. They were all painted dead black, and the last two disks $\left(2 \mathrm{IO}^{\circ}\right.$ and $\left.30^{\circ}\right)$ had the edges of the sectors beveled so as to prevent reflection from them.

With these seven disks the law could be tested at seven points, ranging irregularly from $30^{\circ}$ to $288^{\circ}$ In order to obtain more points of the curve it was decided to cover some of the openings of the disks with thin pieces of blackened aluminum clamped over the openings (Fig. 9). The covers were always placed symmetrically, so that with a disk of six open sectors it was possible to obtain either one-half the total opening by covering the alternate sectors, or to obtain one-third the total

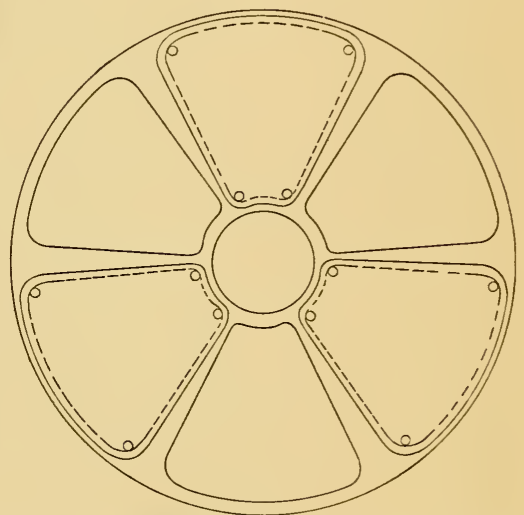

Fig. 9.-Sectored Disk with Three Openings Covered. opening by covering all but two opposite sectors. Moreover, by changing the covers it was possible to obtain the same opening in different ways, i. e., by using different sectors of the same disk.

By this method the following total openings were obtained: $10^{\circ}$, I $5^{\circ}, 30^{\circ}$, from the $30^{\circ}$ disk; $60^{\circ}$ from the $60^{\circ}$ disk, and also from the $180^{\circ}$ disk; $90^{\circ}$ from the $180^{\circ}$ disk and also from the $270^{\circ}$ disk; $\mathrm{I} 20^{\circ}$ from the $240^{\circ}$ disk; $144^{\circ}$ from the $288^{\circ}$ disk; $180^{\circ}, 210^{\circ}$, $240^{\circ}, 270^{\circ}$, and $288^{\circ}$ from the respective disks.

The disks were all carefully calibrated on a circular dividing engine. The opening of each sector of each disk was measured at seven successive radial distances $0.5 \mathrm{~cm}$ apart, over a range of 3 $\mathrm{cm}$, since $3 \mathrm{~cm}$ was approximately the maximum height of the beam 
at the point where it was intercepted by the disk. The mean of the seven readings was taken as the opening of the sector and the height of the disk was always so adjusted that the line from the center of the Nernst to the center of the photometer screen intercepted the disk at the middle point of the region over which it had been calibrated. The average deviation for different radial distances from the mean value for any combination of sectors that was ever used was always under O.I per cent, but owing to difficulties in setting on the edges, the total opening was perhaps not known to an accuracy much better than o.I per cent. The values of the different sectors of the various disks are given in the "Experimental Results."

The sectored disk in all cases, with one or two exceptions which will be noted later, was placed between diaphragms $B$ and $C$ (Fig. $\cdot 5)$ and as close to $B$ as possible. This diaphragm had a circular aperture of $10 \mathrm{~cm}$ and hence screened the motor (except the upper part) and its support from the photometer screen. The distance between the disk and the photometer screen ranged from 20 to $25 \mathrm{~cm}$. Moreover, the sectored disk was always left in position with the open sector in the path of the light for readings intended to give the direct intensity, except when the $30^{\circ}$ disk was used. The $5^{\circ} \mathrm{sec}-$ tors of this disk were too narrow to permit the beam to pass. Measurements made with the larger disks removed, however, failed to show any effect of the stationary disks.

The complete arrangement, except the extension ways, is shown in Fig. Io which was made from a photograph. The hood was removed from the comparison Nernst and is shown standing on the table.

(d) Details of Methods-White Light.-The method of conducting the experiments was as follows: Two seasoned Nernst glowers were mounted in the two sockets and the test Nernst was adjusted so that its center was at the proper height, coinciding very nearly with the axis of the rotator, and the direction of its axis was perpendicular to the line joining its center to that of the photometer screen. The two Nernsts were then brought to incandescence and allowed to burn about an hour. The test Nernst was placed at some definite position and the connecting links between the photometer screen and the comparison Nernst were adjusted until the balance came at 


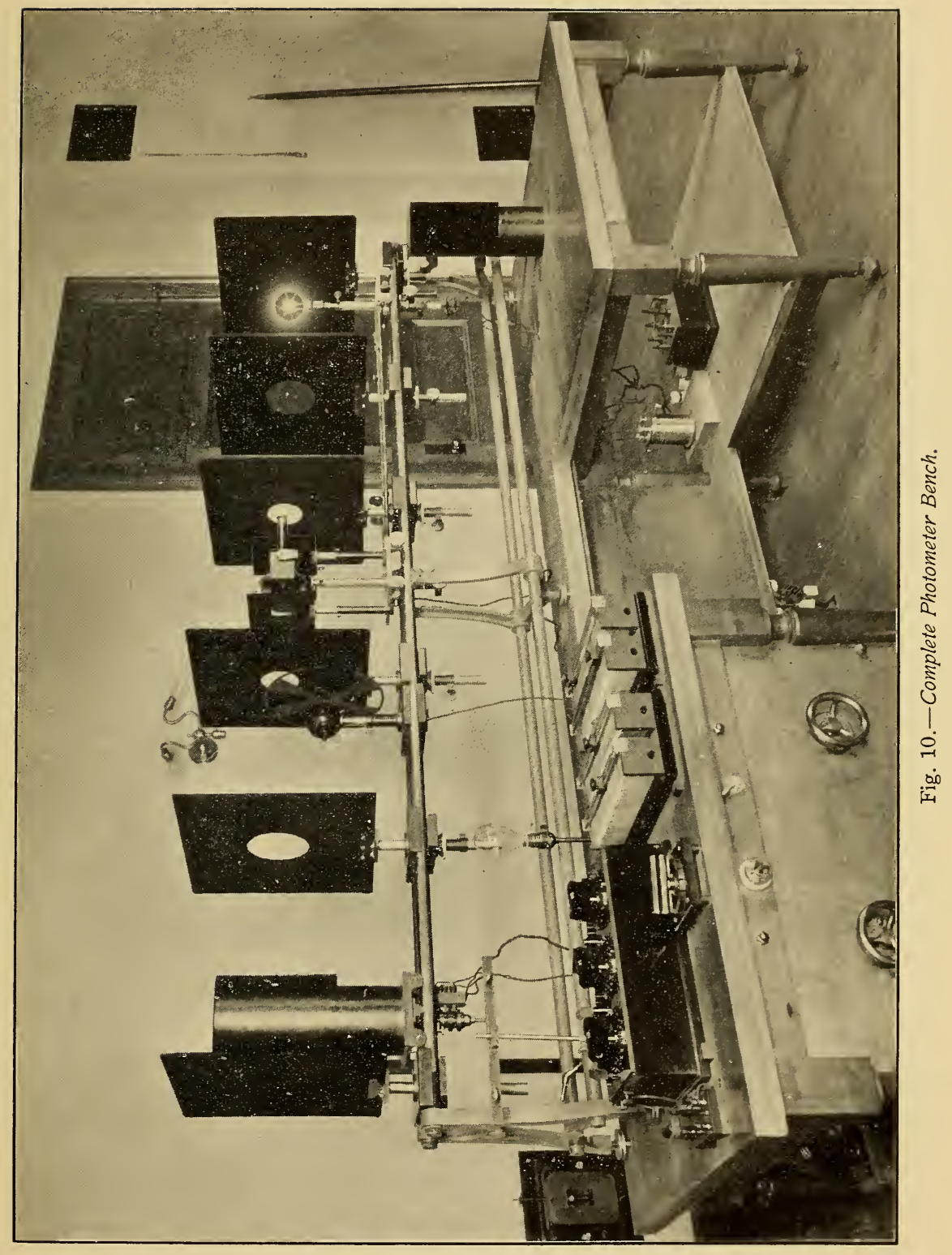


a desirable part of the bar. While one observer maintained the currents constant the other observer made the photometric settings. First, with the disk stationary, a series of three or more readings was made with the Nernst in the $(+)$ position, then a second series with the Nernst in the $(-)$ position, and then two more series, one $(+)$ and the other $(-)$, making in all four series of measurements with the disk stationary. The sectored disk was then set rotating and the test Nernst was moved in nearer to the photometer screen to some position such that the balance came at about the same position on the photometer bar as before. The carriage holding the test Nernst was then clamped to the ways, and kept at this fixed position while the settings for a balance were made. As explained before, the settings were made by moving the photometer screen and comparison Nernst, which moved as a single system remaining at a constant fixed distance apart during the entire experiment. Four series of three readings each were then made as with the disk stationary. This process of alternate stationary and rotating measurements was continued until three groups of stationary readings, and two groups of rotating readings had been made, making a total of twelve series of stationary readings, six $(+)$ and six $(-)$, and eight series of rotating readings, four $(+)$ and four $(-)$. The square of the ratio of the mean distance between the photometer screen and the axis of the rotator, when the disk was rotating, to the mean distance when the disk was stationary, was taken as the effective ratio of the light transmitted by the disk to that incident on it. The comparison of this ratio with the ratio of the angular opening of the disk to $360^{\circ}$ gave the deviation from the law for the disk used.

This method was used for all the disks except in some few sets near the end of the investigation in which only three groups of readings instead of five were made. In all cases after each series of three readings the voltages on the two Nernsts were measured and recorded.

Colored Light.-In the measurements with colored light the method was exactly the same as that used for white light except that a piece of colored glass was introduced into the eyepiece of the photometer. Red, green, and blue glasses were used and measurements were made on three disks, the $240^{\circ}$ disk, the $60^{\circ}$ disk, 
and the $15^{\circ}$ disk. The colored glasses used were not monochromatic, but since to the eye the light appeared distinctly red, or green, or blue, as the case may be, any appreciable error due to one of the colors would probably not be modified greatly by the admixture of relatively small quantities of light of another color.

\section{EXPERIMENTAL RESULTS. ${ }^{1}$}

(a) Effect of Speed.-Before beginning the investigation of Talbot's law, the effect of the speed of rotation of the disk on the illumination of the screen was tested. Since numerous investigators have found that the speed of the disk has no effect on the apparent illumination of the screen provided the speed is greater than a critical speed below which fluctuations in the intensity are visible, it seemed unnecessary to make an extended study of this effect. It was desirable, however, to check the conclusion of previous investigators for a range of speed likely to be used in the experiments. Hence, using successively two disks- the $180^{\circ}$ disk and the $60^{\circ}$ disk-the speed of the disk was varied from the "flicker" point to the maximum speed attainable and no variation of the illumination within the range of experimental error was detected. Subsequently, therefore, no attention was paid to the speed of the disk except to be sure that the speed was sufficiently high, i. e., that the number of alternations of the sectors was sufficiently great to prevent the possibility of a "flicker."

(b) Disks.-In order to show the accuracy of the mechanical construction of the sectored disks, the readings on the $30^{\circ}$ disk for the six separate sectors and at different distances from the periphery of the disk are given in Table II. The first column contains the distances, expressed in centimeters, from the periphery of the disk to the point at which the measurements were made. The other six columns contain the readings on the angular openings of the six sectors numbered from I to VI.

Since the $30^{\circ}$ disk contained the smallest sectors of all the disks it had to be made and measured most carefully of all, for small deviations of the edges of the sectors from straight radial lines would produce relatively large errors in the angular openings. The absolute angle need not be made to agree very closely with the nominal value, as the subsequent calibration will give the true value of

${ }^{1}$ I wish to express my indebtedness to my assistants, Mr. F. E. Cady and Mr. A. H. Schaaf, for valuable assistance both in observations and computations. 
the opening, but it is very necessary that the edges be made approximately radial and quite straight, so that the mean of the seven measurements made every $5 \mathrm{~mm}$ may represent the mean value of the opening. It is seen from Table II that the maximum range of variation at different radial distances for most of the sectors is only

TABLE II.

Calibration of $30^{\circ}$ Disk.

\begin{tabular}{|c|c|c|c|c|c|c|}
\hline $\begin{array}{c}\text { Distance from } \\
\text { Periphery }\end{array}$ & I & II & III & IV & V & VI \\
\hline \multicolumn{7}{|l|}{$\mathrm{cm}$} \\
\hline 3.0 & $5^{\circ} 04^{\prime} 48^{\prime \prime}$ & $5^{\circ} 03^{\prime} 46^{\prime \prime}$ & $5^{\circ} 03^{\prime} 02^{\prime \prime}$ & $5^{\circ} 04^{\prime} 45^{\prime \prime}$ & $5^{\circ} 05^{\prime} 28^{\prime \prime}$ & $5^{\circ} 06^{\prime} 24^{\prime \prime}$ \\
\hline 3.5 & 0508 & 0354 & 0300 & 0428 & 0527 & 0622 \\
\hline 4.0 & 0517 & 0350 & 0312 & 0426 & 0523 & 0640 \\
\hline 4.5 & 0521 & 0342 & 0300 & 0420 & 0514 & 0634 \\
\hline 5.0 & 0506 & 0352 & 0254 & 0414 & 0528 & 0657 \\
\hline 5.5 & 0510 & 0351 & 0245 & 0414 & 0533 & 0710 \\
\hline 6.0 & 0514 & 0351 & 0254 & 0428 & 0544 & 0708 \\
\hline Mean ...... & $\begin{array}{lll}50509 & 05\end{array}$ & $\begin{array}{lll}5 & 0349\end{array}$ & 50258 & 50425 & $\begin{array}{lll}50528\end{array}$ & 50645 \\
\hline
\end{tabular}

about $3 \mathrm{O}^{\prime \prime}$ or I part in 600 . The average deviation from the mean opening would be well under I part in $\mathrm{I}$,ooo.

As stated above, the disks were always mounted in such a position that the beam of light passed through the calibrated part of the sectors.

Measurements similar to those for the $30^{\circ}$ disk were made on all the disks, the final results of which in the form in which they were used are given in Table III. The first column contains the various disks. The second column contains the nominal angles obtained from the different disks, and the third column gives the sectors that were employed to obtain these angles. In the fourth column are given the ratios of the actual angles to $360^{\circ}$. These ratios, compared with the ratios of the squares of the distances obtained in the experiments, gave the errors in the law. 
TABLE III.

\begin{tabular}{|c|c|c|c|}
\hline Disks & Nominal Angles & Sectors Used & $\begin{array}{l}\text { Corresponding Angles } \\
\div 360^{\circ}\end{array}$ \\
\hline \multirow[t]{6}{*}{$30^{\circ}$} & $30^{\circ}$ & I-VI & 0.08466 \\
\hline & $15^{\circ}$ & I, III, V & 0.04229 \\
\hline & $15^{\circ}$ & II, IV, VI & 0.04236 \\
\hline & $10^{\circ}$ & I, IV & 0.02822 \\
\hline & $10^{\circ}$ & II, V & 0.02821 \\
\hline & $10^{\circ}$ & III, VI & 0.02823 \\
\hline $60^{\circ}$ & $60^{\circ}$ & I-III & 0.16914 \\
\hline \multirow[t]{6}{*}{$180^{\circ}$} & $180^{\circ}$ & I-VI & 0.5012 \\
\hline & $90^{\circ}$ & I, III, V & 0.2506 \\
\hline & $90^{\circ}$ & II, IV, VI & 0.2507 \\
\hline & $60^{\circ}$ & I, IV & 0.16697 \\
\hline & $60^{\circ}$ & II, V & 0.16718 \\
\hline & $60^{\circ}$ & III, VI & 0.16710 \\
\hline $210^{\circ}$ & $210^{\circ}$ & I-VI & 0.5841 \\
\hline \multirow[t]{3}{*}{$240^{\circ}$} & $240^{\circ}$ & I-VI & 0.6683 \\
\hline & $120^{\circ}$ & I, III, V & 0.3341 \\
\hline & $120^{\circ}$ & II, IV, VI & 0.3342 \\
\hline \multirow[t]{4}{*}{$270^{\circ}$} & $270^{\circ}$ & I-VI & 0.7508 \\
\hline & $90^{\circ}$ & I, IV & 0.2501 \\
\hline & $90^{\circ}$ & II, V & 0.2504 \\
\hline & $90^{\circ}$ & III, VI & 0.2503 \\
\hline \multirow[t]{3}{*}{$288^{\circ}$} & $288^{\circ}$ & I-VI & 0.8000 \\
\hline & $144^{\circ}$ & I, III, V & 0.4000 \\
\hline & $144^{\circ}$ & II, IV, VI & 0.4000 \\
\hline
\end{tabular}

(c) White Light.-In order that the exact method of observation and computation may be known, the following series of measurements of June 2, I905, copied from the laboratory record book, is given:

\section{SERIES XXV.}

$60^{\circ}$ disk, total opening 60.89: $\frac{60.89}{360}=0.169 I 4 . \quad 88$-watt Nernst No. 9 on left at o when disk is stationary, and at 7 I. 5 when disk is 
rotating. 88-watt Nernst No. Io on right, as comparison lamp, at fixed distance I $9.9 \mathrm{~cm}$ from photometer screen.

\begin{tabular}{|c|c|c|c|c|c|}
\hline \multicolumn{3}{|c|}{$60^{\circ}$ disk stationary. } & \multicolumn{3}{|c|}{ Nernst No. 9 at o. } \\
\hline$(+)$ & \multirow{4}{*}{ I 22.78} & Volt. & $(+)$ & \multirow{4}{*}{ I 22.80} & Volt. \\
\hline I22.97 & & No. IO $=\mathrm{III}$.OI & 122.97 & & No. IO $=$ II 10.99 \\
\hline .82 & & No. $9=117.08$ & .63 & & No. $9=117.08$ \\
\hline $\begin{array}{l}.56 \\
.75\end{array}$ & & & & & \\
\hline$(-)$ & \multirow{4}{*}{ I22.19 } & Volt. & $(-)$ & \multirow{4}{*}{121.99} & Volt. \\
\hline I 22.33 & & No. $10=$ I 10.98 & I 22.03 & & No. $10=I I I .00$ \\
\hline .07 & & No. $9=\operatorname{I} 7.08$ & I. 98 & & No. $9=$ I I 7.07 \\
\hline .17 & & & I. 97 & & \\
\hline \multicolumn{3}{|c|}{$60^{\circ}$ disk rotating. } & \multicolumn{3}{|c|}{ Nernst No. 9 at 71.5 . } \\
\hline$(-)$ & \multirow[b]{3}{*}{ I 21.87} & Volt. & $(-)$ & \multirow[b]{3}{*}{121.84} & Volt. \\
\hline I $21.9 \mathrm{I}$ & & No. IO $=$ III.OI & I2I.9I & & No. IO $=$ III.$\infty 0$ \\
\hline .89 & & No. $9=\operatorname{II} 7.07$ & .78 & & No. $9=117.07$ \\
\hline & \multirow{5}{*}{ I 22.26} & & & \multirow{5}{*}{ I 22.24} & \\
\hline$(+)$ & & Volt. & $(+)$ & & Volt. \\
\hline I 22.44 & & No. $10=\operatorname{III} . \infty$ & 122.38 & & No. $10=\mathrm{I} 10.99$ \\
\hline .22 & & No. $9=\operatorname{II} 7.07$ & .16 & & No. $9=117.04$ \\
\hline .23 & & & .17 & & \\
\hline & \multicolumn{2}{|c|}{$60^{\circ}$ disk stationary. } & \multicolumn{3}{|c|}{ Nernst No. $g$ at o. } \\
\hline$(+)$ & \multirow{4}{*}{122.69} & Volt. & $(+)$ & \multirow{4}{*}{122.85} & Volt. \\
\hline $122.6 \mathrm{I}$ & & No. $10=$ III.OO & I 22.97 & & No. $I 0=I 10.99$ \\
\hline .67 & & No. $9=117.03$ & $.7 \mathrm{I}$ & & No. $9=\operatorname{II} 7.06$ \\
\hline .80 & & & $\begin{array}{l}.99 \\
.73\end{array}$ & & \\
\hline$(-)$ & \multirow{5}{*}{ I 22. I I } & Volt. & $(-)$ & \multirow{5}{*}{ I22.06 } & Volt. \\
\hline 122.33 & & No. $I 0=I I 0.98$ & I 22.02 & & No. $10=110.97$ \\
\hline 2.10 & & No. $9=\operatorname{II} 7.02$ & .13 & & No. $9=\operatorname{II} 7.03$ \\
\hline I.94 & & & .02 & & \\
\hline \multirow{2}{*}{$\begin{array}{l}1.94 \\
2.07\end{array}$} & & & & & \\
\hline & \multicolumn{2}{|c|}{$60^{\circ}$ disk rotating. } & \multicolumn{3}{|c|}{ Nernst No. 9 at $7 I .5$. } \\
\hline$(-)$ & \multirow{4}{*}{121.82} & Volt. & $(-)$ & \multirow{4}{*}{121.85} & Volt. \\
\hline І21.77 & & No. $10=110.99$ & I 21.89 & & No. $10=$ I 10.99 \\
\hline .87 & & No. $9=117.04$ & .87 & & No. $9=\operatorname{II} 7.04$ \\
\hline .82 & & & .80 & & \\
\hline \multirow{2}{*}{$\begin{array}{c}(+) \\
\text { I22.3 I }\end{array}$} & & Volt. & $(+)$ & & Volt. \\
\hline & & No. $10=110.99$ & 122.20 & & No. $10=110.98$ \\
\hline .37 & $\mathrm{I} 22.30$ & No. $9=\operatorname{II} 7.04$ & .31 & I 22.24 & No. $9=117.05$ \\
\hline .22 & & & $.2 \mathrm{I}$ & & \\
\hline & $60^{\circ}$ dis & ionary. & & Nerns & 9 at 0. \\
\hline$(+)$ & & Volt. & $(+)$ & & Volt. \\
\hline I 22.73 & & No. $10=110.98$ & I 22.83 & & No. $I 0=\operatorname{III} .00$ \\
\hline $.8 \mathrm{I}$ & 2028 & No. $9=\operatorname{II} 7.02$ & .64 & 122.68 & No. $9=117.01$ \\
\hline $\begin{array}{l}.97 \\
.72\end{array}$ & & & .57 & & \\
\hline
\end{tabular}


$60^{\circ}$ disk stationary.

$\begin{array}{rr}(-) & \\ \text { I22.0I } & \\ 2.29 & \\ 1.88 & 121.99 \\ 1.87 & \\ 1.89 & \end{array}$

Volt.

No. $10=110.99$

No. $9=117.02$

Nernst No. 9 at 0 .

$\begin{array}{rr}(-) & \\ 121.97 & \\ 2.01 & 121.92 \\ 1.77 & \\ 1.93 & \end{array}$

Volt.

No. IO $=$ III.OI

No. $9=117.02$

\section{Computations.}

Disk stationary.

$$
\begin{aligned}
& \begin{array}{rr}
122.7^{8} & 122.79 \\
.80 & 122
\end{array}
\end{aligned}
$$

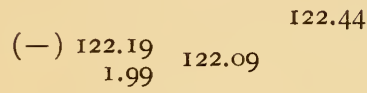

$$
\begin{aligned}
& \begin{array}{rr}
\hline \text { (t) } 122.69 & \\
.85 & 122.77
\end{array}
\end{aligned}
$$

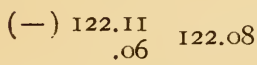

$$
\begin{aligned}
& \begin{array}{rr}
\hline+(+) \begin{array}{r}
22.8 \mathrm{I} \\
.68
\end{array} & \mathrm{I} 22.74
\end{array} \\
& \begin{array}{rr}
(-) & 121.99 \\
.92 & \text { 121.96 }
\end{array}
\end{aligned}
$$

Disk rotating.

$$
\begin{aligned}
& \begin{array}{rr}
\text { (+) } \begin{array}{r}
22.26 \\
.24
\end{array} & \mathrm{I} 22.25
\end{array} \\
& \begin{array}{rrr}
(-) & & \text { 121.87 } 22.06 \\
.84 & \text { 121.86 }
\end{array} \\
& \begin{array}{rrr}
\hline(+) \begin{array}{rr}
222.30 \\
.24
\end{array} & \text { I22.27 } & \\
& & \text { I } 22.06
\end{array} \\
& \begin{array}{rr}
(-) & \text { I2I.82 } \\
.85 & \text { 12 } 1.84
\end{array}
\end{aligned}
$$

Mean stationary setting ....... I 22.40 Position of Nernst carriage.... 0.00

Distance $=\ldots \ldots \ldots \ldots \ldots$ I22. 40 Correction to bar ........... $-0.4 \mathrm{I}$

Corrected distance $=\ldots \ldots \overline{\text { I } 2 \text { I. } 99}$
Mean rotating setting....... 122. 06

Position of Nernst carriage..... 7 7. 50

Distance $=\ldots \ldots \ldots \ldots \ldots$ 50. 56

Correction to bar........... -0.32

Corrected distance $=\ldots . \quad 50.24$

$$
\begin{aligned}
\left(\frac{50.24}{121.99}\right)^{2} & =0.1696 \mathrm{I} . \\
\frac{60.89^{\circ}}{360^{\circ}} & =\frac{0.169 \mathrm{I} 4}{+47}=+0.28 \% . \quad \text { Deviation from Talbot's law. }
\end{aligned}
$$

This method of observation and computation was followed throughout the investigation. A great number of different Nernst glowers, both of the 88-watt type and of the 44-watt type, were used. The choice between an 88-watt glower and a 44-watt glower for the comparison lamp was determined by convenience. For the test lamp, however, measurements were made with both types with the larger angular openings in order to test the effect of change in the absolute illumination of the screen. Thus with the $288^{\circ}, 270^{\circ}$, $240^{\circ}$, and $180^{\circ}$ disks measurements were made with both the $44^{-}$ 
watt and the 88-watt glowers, each at two different distances, so that the extreme illuminations used were in the ratio of $\mathrm{r}: 4$. With the $60^{\circ}$ disk illuminations in the ratio of $\mathrm{r}: 2$ were used, but in no case was there any evidence of an effect due to absolute intensity of illumination. These variations in the intensity of illumination were not very large, so that it would be interesting to study the effect of large changes in the intensity of illumination, particularly for disks with small openings. In my observations with openings smaller than $60^{\circ} 88$-watt glowers were always used, since even with them the illumination of the photometer screen was quite small, because of the necessarily long distance. Thus with the $10^{\circ}$ opening the distance between the test Nernst and the screen was approximately $300 \mathrm{~cm}$ when the disk was unmounted and only $50 \mathrm{~cm}$ when the disk was rotating. Moreover, because of this great range of distance but one distance for each position could be used conveniently.

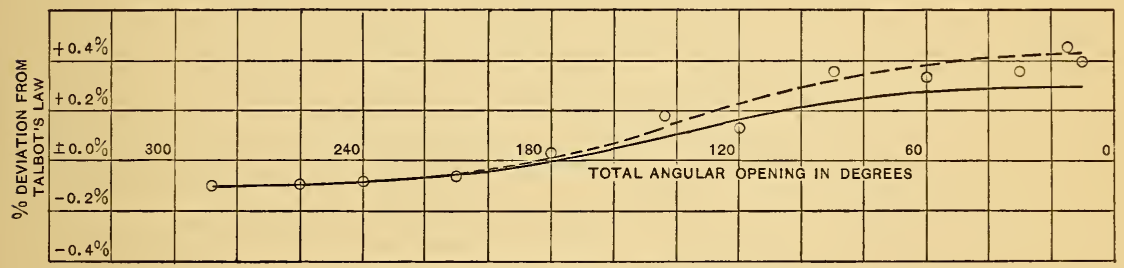

Fig. 11.-Deviation from Talbot's Law.

The results obtained with the various angular openings are shown in Table IV, in which $(+)$ means that the disk apparently let through more light than would be expected from Talbot's law. It should be stated that the order in which the disks were used was most irregular. Several of them, for example, were tested both near the beginning and near the end of the investigation, which extended over a period of ten or twelve months.

The mean values for the different angular openings are plotted in the form of a curve in Fig. II, in which abscissas are angular openings, and ordinates are percentage deviations from the law of Talbot. The dotted curve represents the values given in Table IV.

It is seen that for all angular openings from $288^{\circ}$ to $10^{\circ}$ the law is rerified to within 0.5 per cent. Attention should be called, however, to the form of the curve. Since the average deviation of the readings for any one angle was in no case as large as 0.2 per cent, 
the probable errors of the measurements are in all cases under O.I per cent, while the observed errors in the law are as large as 0.4 per cent. Because the probable errors are less than o.I per cent, it does not necessarily follow, however, that the results are correct to the

TABLE IV.

Percentage Deviations from Talbot's Law Using White Light.

\begin{tabular}{|c|c|c|c|c|c|c|}
\hline $\begin{array}{l}\text { Total Angular Open- } \\
\text { ings ..................... }\end{array}$ & $288^{\circ}$ & $270^{\circ}$ & $240^{\circ}$ & $210^{\circ}$ & $x 88^{\circ}$ & $144^{\circ}$ \\
\hline & $\begin{array}{l}-0.16 \% \\
+.01 \\
-.09 \\
-.12\end{array}$ & $\begin{array}{c}-0.05 \% \\
.03 \\
.06 \\
.16\end{array}$ & $\begin{array}{l}-0.05 \% \\
-.12 \\
-.17 \\
+.01\end{array}$ & $\begin{array}{l}-0.06 \% \\
-.05\end{array}$ & $\begin{array}{l}+0.10 \% \\
+.14 \\
-.15 \\
-.10 \\
+.13 \\
+.11\end{array}$ & $\begin{array}{c}+0.24 \% \\
.25 \\
.09\end{array}$ \\
\hline $\begin{array}{l}\text { Average variation } \\
\text { from the mean.. }\end{array}$ & $\begin{array}{l}-0.09 \\
\pm 0.05\end{array}$ & $\begin{array}{l}-0.08 \\
\pm .04\end{array}$ & $\begin{array}{l}-0.08 \\
\pm .06\end{array}$ & $\begin{array}{l}-0.06 \\
\pm .00\end{array}$ & $\begin{array}{l}+0.04 \\
\pm .11\end{array}$ & $\begin{array}{l}+0.19 \\
\pm .07\end{array}$ \\
\hline
\end{tabular}

Table IV, continued.

\begin{tabular}{|c|c|c|c|c|c|c|}
\hline $\begin{array}{l}\text { Total Angular Open- } \\
\text { ings ..................... }\end{array}$ & $120^{\circ}$ & $90^{\circ}$ & $60^{\circ}$ & $30^{\circ}$ & $15^{\circ}$ & $10^{\circ}$ \\
\hline & $\begin{array}{c}+0.22 \% \\
.04\end{array}$ & $\begin{array}{c}+0.37 \% \\
.51 \\
.39 \\
.33 \\
.40 \\
.45 \\
.03 \\
.41\end{array}$ & $\begin{array}{c}+0.54 \% \\
.15 \\
.20 \\
.20 \\
.20 \\
.28 \\
.65 \\
.44\end{array}$ & $\begin{array}{c}+0.35 \% \\
.37 \\
.39\end{array}$ & $\begin{array}{c}+0.38 \% \\
.63 \\
.52 \\
.55 \\
.61 \\
.26 \\
.26 \\
.40\end{array}$ & $\begin{array}{c}+0.14 \% \\
.52 \\
.38 \\
.61 \\
.39\end{array}$ \\
\hline $\begin{array}{l}\text { Average variation } \\
\text { from the mean.. }\end{array}$ & $\begin{array}{l}+0.13 \\
\pm .09\end{array}$ & $\begin{array}{l}+0.36 \\
\pm .09\end{array}$ & $\begin{array}{l}+0.33 \\
\pm .16\end{array}$ & $\begin{array}{l}+0.37 \\
\pm .01\end{array}$ & $\begin{array}{l}+0.45 \\
\pm .13\end{array}$ & $\begin{array}{l}+0.41 \\
\pm .13\end{array}$ \\
\hline
\end{tabular}

same accuracy. Some constant source of error might possibly be present. It will be noticed from the table that approximately the same deviation was found for all the openings less than $\mathrm{I} 2 \mathrm{O}^{\circ}$. Now, in all the measurements on these angles, the rotating readings were 
taken with the test Nernst about $50 \mathrm{~cm}$ from the photometer screen, at which distance the entire system was very much congested. Hence, it seemed possible that some stray light might have penetrated to the screen which would not have reached the screen when a longer distance was used as in the stationary readings. In particular the photometer screen itself reflects light back on the diaphragms and on the solid sectors of the disk, and since these were necessarily very close to the screen when the test Nernst was only $50 \mathrm{~cm}$ away, the apparent deviation from the law might possibly be due in part to this stray light.

An attempt was made to measure the effect of this stray light by cutting off the direct rays from the Nernst, but it was found very difficult to reproduce the conditions, and so this method of attack was abandoned. A second method which seemed productive of results, but which could not be carried as far as desired for want of time, consisted in using longer distances for the $90^{\circ}$ disk and in comparing the $15^{\circ}$ disk with the $180^{\circ}$ disk, which has an error of +0.04 per cent. Only a few observations were made, but they seemed to be in the right direction. Thus, with the $90^{\circ}$ disk four determinations at a much greater distance than that used before gave as the errors +0.38 per cent, +0.14 per cent, 0.09 per cent, and +0.18 per cent, with a mean of +0.20 per cent, as against +0.36 per cent in the previous determinations. Similarly two measurements of the $15^{\circ}$ disk against the $180^{\circ}$ disk, the shortest distance between the test Nernst and the photometer screen being about $73 \mathrm{~cm}$ instead of $50 \mathrm{~cm}$, as was used in the previous measurements, gave as the errors +0.22 per cent and +0.49 per cent, with a mean of +0.36 per cent. This is only 0.09 per cent lower than the mean value of the previous determinations, but it is in the right direction.

If, now, to the above considerations we add that of the deviations of the radiation of a cylinder from the inverse square law, which are also in the right direction, we reduce the error for the small openings still further. For a cylinder $20 \mathrm{~mm}$ long and I $\mathrm{mm}$ radius the error for the distances used with the $10^{\circ}$ disk would be +0. II per cent. For an 88 watt Nernst ${ }_{5} \mathrm{~mm}$ long and $0.6 \mathrm{~mm}$ radius the error probably would be but slightly less than +o.I I per cent, or about +0.08 per cent or +0.09 per cent. Similar errors would be 
present in the measurements of the other disks, so that the complete curve of Fig. I I would be lowered by a small amount, the lowering being greatest at $10^{\circ}$ where it would amount to about 0.08 per cent, and least at $288^{\circ}$, where it would be approximately zero.

This lowering of the curve due to the deviation from the inverse square law combined with that indicated by the experiments described just above would seem to justify a total lowering of the curve sufficient to bring it within the limits +0.3 per cent and -0.3 per cent as shown in the solid curve of Fig. II.

No attempt has been made to investigate the effect of diffraction at the edges of the disk. This might possibly affect the result to some small extent.

In order to determine whether the personal equation entered to any extent into the results obtained, several sets of readings were made by a second observer. With the $2 \mathrm{IO}^{\circ}$ disk he made but one set of measurements obtaining the result +0.04 per cent. With the $\mathrm{I} 44^{\circ}$ opening he obtained $+0.2 \mathrm{I}$ per cent; with the $\mathrm{r} 2 \mathrm{O}^{\circ}$ opening, +0.16 per cent and +0.20 per cent; with the $90^{\circ}$ opening, +0.12 per cent, +0.26 per cent, and -0.I2 per cent; with the $60^{\circ}$ opening + O.I 4 per cent; and with the $15^{\circ}$ opening + o.II per cent, +0.29 per cent, +0.33 per cent, and +0.37 per cent. His readings are thus in the same direction as my own and for the most part agree with them, although on the whole they show somewhat smaller deviations, particularly for the smaller openings.

(d) Colored Light.- - In the investigation of the law with colored. light it was thought sufficient to determine whether for several points on the curve the values obtained with colored light are in approximate agreement with the corresponding values for white light. The same method of observation as that for white light was used, but the error of observation was very much larger, partly because of the color and partly because of the reduced intensity which made observations on the $15^{\circ}$ disk yery difficult. The $240^{\circ}$, $60^{\circ}$, and $15^{\circ}$ openings were used, and each was tested with red, green, and blue light by inserting pieces of glass in the eyepiece of the photometer. 'The red glass was ordinary ruby glass and was found on examination with a spectroscope to transmit very little other than red, although the band in the red was quite broad. The green glass was supposed to be a very high grade of monochromatic 
glass, but it transmitted much light of other colors, as did also the cobalt blue glass used for the blue.

In connection with the measurements with colored light it was thought desirable to make a few experiments with color differences on the two sides of the screen as this condition always existed in Ferry's experiments when he obtained the large errors. The test lamp, as in the previous experiments, was a Nernst glower at normal current. The comparison lamp, however, was a $16 \mathrm{cp}$ anchored oval, II 8 volt, 3.5 watt per candle incandescent lamp burning at different voltages ranging from II 6 to IO2 volts. The color difference was very marked when the incandescent lamp was at normal voltage, but in order to insure the detection of any error that might exist, the incandescent lamp was burned at 102 volts in the measurements with the $15^{\circ}$ disk. At this voltage the contrast in color was very great and yet no greater deviations than those for white light on both sides of the screen were detected.

TABLE V.

Deviations from Talbot's Law Using Red, Green, and Blue Light, and Color Difference.

\begin{tabular}{|c|c|c|c|c|c|c|}
\hline & $240^{\circ}$ & Means & $60^{\circ}$ & Means & $15^{\circ}$ & Means \\
\hline Red light ...... & $\begin{array}{l}+0.09 \% \\
-.07\end{array}$ & $+0.01 \%$ & $\begin{array}{c}+0.37 \% \\
.86\end{array}$ & $+0.62 \%$ & $\begin{array}{l}+1.06 \% \\
-.25 \\
+.52 \\
*+0.58\end{array}$ & $+0.44 \%$ \\
\hline Green light. & $\begin{array}{l}-0.09 \\
+0.06\end{array}$ & -0.02 & $\begin{array}{r}+0.51 \\
.43\end{array}$ & +0.47 & $\begin{array}{r}+0.05 \\
.42\end{array}$ & +0.24 \\
\hline Blue light $\ldots . .$. & $\begin{array}{r}+0.01 \\
-.13\end{array}$ & -0.06 & $\begin{array}{r}+0.41 \\
.35\end{array}$ & +0.38 & $\begin{array}{r}+0.30 \\
.70 \\
*+0.47\end{array}$ & +0.50 \\
\hline Color difference.. & $\begin{array}{l}+0.21 \\
-0.14\end{array}$ & +0.04 & $\begin{array}{r}+0.63 \\
.45 \\
.30\end{array}$ & +0.46 & $\begin{array}{r}+0.57 \\
.56\end{array}$ & +0.56 \\
\hline
\end{tabular}

In making the measurements with color difference the absorption strips were removed from the Lummer-Brodhun photometer and the setting was made for a match, instead of for equal contrast. The same openings were used as in the experiment with the red, green, 24353-No. I- $66-3$ 
and blue light. All of the results of the experiments with colored lights, and of those in which there was a color difference on the two sides of the screen are contained in Table V. The first column contains the four different conditions under which the experiments were made. In the second, fourth, and sixth columns are given the corresponding results, and in the third, fifth, and seventh columns are given the means of the values in the second, fourth, and sixth columns, respectively. The observations marked with an asterisk were made by the second observer and are not included in the means.

From a comparison of Tables IV and V it is seen that within the range of experimental error the deviations from Talbot's law are the same for white and colored light and for difference in color on the two sides of the screen. It would be well, however, to make further experiments on colored light in order to reduce the probable error, and obtain results more nearly comparable with the results for white light.

\section{CONCLUSIONS.}

The results of this investigation may be summarized as follows:

(I) Talbot's law, in its application to a rotating sectored disk, is verified for white light for all total angular openings between $288^{\circ}$ and $10^{\circ}$, to within a possible error of 0.3 per cent, which probably expresses the limit of accuracy of the experiments.

(2) The observed deviations from the law for red, green, and blue light are of the same order of magnitude as those for white light, and hence 'Talbot's law is verified for red, green, and blue light, though not to such a high accuracy as for white light. Moreover, a difference in color on the two sides of the photometer screen produces no appreciable change in the observed deviation from the law. 